\title{
Women Participation In Community Development Programs In Urban Area In Balochistan
}

\author{
Siraj Bashir \\ Department of Social Work \\ University of Balochistan
}

\begin{abstract}
The aim of research study was to examine the participation of women in community development programs in urban area in Balochistan. This research study tried to know the influencing motives women to participate in community development programs. From a past viewpoint, women have experienced and survived many hard conditions. These have included deprivation, poverty and injustice, all of which have led to their poor socio-economic status. The study used quantitative methods. The purposive sampling method was used. Data were collected using the interview schedule for quantitative data. The total number of respondents were 100 from various NonGovernmental Organizations (BRSP, IDO, Mercy Corps). According to the study findings the participation of women in community development programs had a very positive and result oriented effect because though these various programs they ensure livelihood for their families and women resources were also developed. The study recommended that women participation should be ensured towards sustainable development in Balochistan.
\end{abstract}

Keywords: Women Participation, Community Development Programs, Balochistan.

$$
\begin{aligned}
& \text { تلخيص }
\end{aligned}
$$

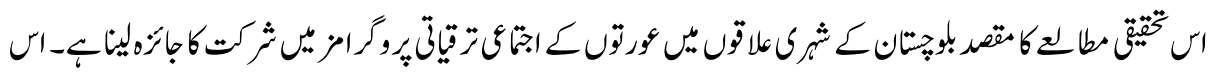

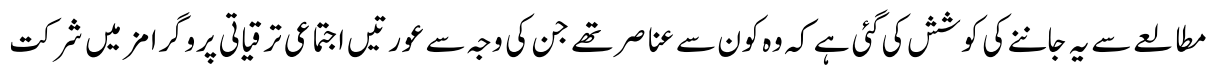

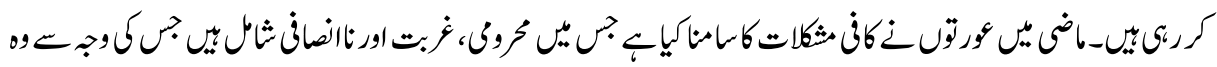

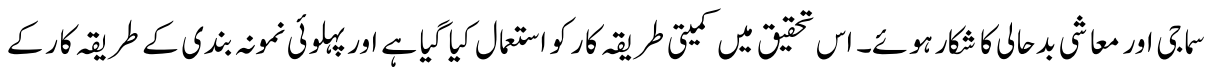

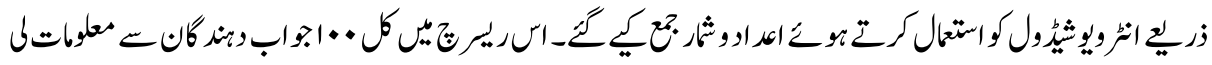

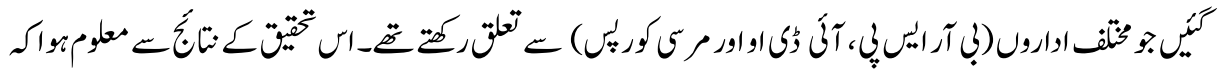

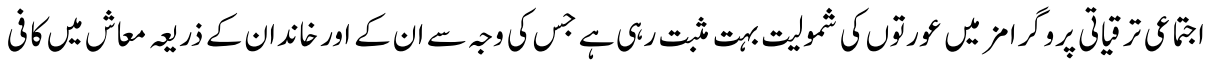

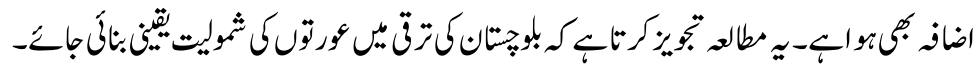

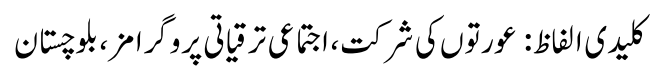




\section{Introduction}

The term of community participation in development is very famous and important to the development process. The governments and international organizations tries to involve local communities in development or community development programs which give positive effect in their life. The members of communities may participate in several programs such as education, health, roads and etc development. According to United Nations (1973), community participation is a process through which voluntary efforts by local communities be give in case or in kind in public programs. The above definition analysis community participation as bottom-up approach starts from the local people themselves and not forced by outsiders. The community participation must be active involvement of local people (men, women, youth, old age, and etc) in a real participation and not only presence. The local community representatives particularly deprived sectors must be involved from designing, implementation, monitoring, evaluating community development programs.

Community development is known as one of the planned approaches for socio-economic change. Through this approach, all members of the community are involved, mainly of the areas where activities are being happened. Community development approach gives equal opportunities to all people of the community to improve their living condition and also provide a well-organized platform to use locally available resources in the more systemic way. Community development is recognized as a collective and people-centered approach that gives the same possibilities to people to work jointly for development and allow them to deal with the issues with suitable solutions (Pawan, 2014).

The role of women in community development has become very crucial and can be the means of reducing gender inequality, ending thousand years of discrimination and developing the whole community. In some parts of the world, they have become as leaders in community development and successfully achieved the abilities and skills that have brought constructive changes to their targeted communities. Women carry out very important roles in developing and keeping strong relationships and harmonization in their communities (Korten, 1990). Gender impartiality is shaped by many aspects, like rules, social norms, social perceptions, defensive claims, and private and family attributes. The influence and size of every issue differ across cultures and countries. In developing countries above all, boosting gender equality will be tough (Ismail, 1999).

While leading the community, women face social, cultural, political and economic challenges and barriers and in some cases defeating those challenges and barriers become their inspiration. On another side, their broad and participatory approaches have persuaded the process of community development, women's contributions have been neglected in politics and comparatively inactive in community development programs because of socio-economic and cultural limitations (Kenny, 1994). 
Constant change in the socio-economic conditions of developing countries encourage different communities to plan their strategies in order to uplift their status that not only promotes their social mobility but also provides strength to the particular society and community (Kabeer, 2005). For this purpose, women is the only gender that mobilizes and helps in functionalizing the process of community development through their interminable tiresome efforts.

Pakistan is a third world country that is constantly developing since its existence and recent transition of power through democratic way marked its milestone of strengthening of democracy that is quite an encouraging sign for the development of communities individually and society and nation as a whole that lays foundation for a better future for the upcoming generations of the country. Now then, Pakistan is a country that faced severe types of constitutional attacks in past and got its constitution rebuilt thrice. As Noreen (2011) mentioned that, during that process, a number of laws were reformed for women empowerment and participation as Pakistan is the state founded on the name of a religion that provided women with their basic rights for the first time ever in history, therefore those laws were thoroughly constituted under the guidance of the religious instructions and were for the betterment of women. Yet it is observed that the rights of women could not be secured and gender discrimination is still at its peak. Women's rights violation is normal and no progress has been observed yet. Despite the fact that rural women have suffered a lot in this whole procedure but when it comes to the urban women, deprivation is not less here too as they were exaggerated by country laws; those forced by homelands as well as those forced by their political and religious leaderships. According to the United Nations report (2007), more than seventy percent of the population of the world's living in the Third World with socio-economic issues and majority of them from urban areas. According to 2018 national census, 34 percent of the Pakistan population lives in urban areas, with more than half of this population being women. Besides that, lack of support from their opposite gender, low confidence and self-belief, minimum awareness towards their basic, social, moral, socio-economic and national rights and less representation of women at political and governmental level ignites the heat more than ever and enhances the severity of the problem.

In most countries like Pakistan particularly Balochistan province, women contributions are now being known towards economy and others aspects of life and development especially in urban communities. All world specially the Third World countries are now focusing on women participation it has been established that there will be no any progress in community development unless the women are included in the work process. The contributions women make must be taken into consideration because history shows that families have survived because women were always there and the duties they perform indicate that they are equally essential to their communities as oxygen for human life (Sultan, 2009). 
In spite of these all above described situations, urban women have gone a long way in community development. Through their constant efforts for remodeling the society, women have begun to contribute to the improvement of their lives and the enhancement of their participation in community development. The researcher interested with the above topic because the concept woman participation in community development programs has been an important concept for more than three decade now. The government are now encouraging the departments and NGOs to involve woman in community development programs. It believes that for the community/ province/ country to get sustainable development there must be woman's participation in programs. Therefore, the researcher wanted to know women participation in community development programs in Balochistan. How does the socio-economic development achieved through women themselves with the assistance from the government and NGOs. The researcher also wanted to investigate whether the women participation initiated by the community themselves or influenced/forced by government.

\section{Objectives of the Study}

Following objective are going to be the main focus of the study.

- To know the role of urban women in the community development programs in Balochistan.

- To obtain the motivating reasons for women's participation in community development with reference to their socio-economic rights

\section{Literature Review}

\section{Community}

As Dunham (1970), defined community as a 'composition of people who live within a geographical bounded area, who are involved in social interaction and who have psychological ties with each other and with the place where they live'. Kathleen M. McQueen (2001) defined community as 'A general definition of community come outs as a group of individuals with varied features who are linked by social ties, share ordinary viewpoints, and keep in combined accomplishment in geographical locations or settings.

Besides that, Ferrinho (1980) defined Community by focusing on the following characteristics:

- A way of life that modifies institutions, common values and interests of residents (Cultural Approach).

- A network of social interaction within which people relate to one another (Sociological Approach 
- A system for a set of common individual identifications (Psychological Approach),

- An abode from where human population obtain energy that is required for living and surviving (Ecological Approach).

Now, referenced to the following study, the explanation of Ferrinho works hand and glove and is believed to be adopted throughout the study and all other phenomena are going to be elaborated accordingly.

\section{Development}

Term Development is an expanded ocean of knowledge and a difficult one to define. Various authors have proposed various definitions for the term 'Development'. Some view development from the physical, social, moral, clinical, economic, physical, communal, and social perspectives. Hugo (1984), for example regards development as a human activity considered from a variety of perspectives and can be linked with three concepts, i.e.

Old proves of development projects were successfully undertaken in numerous communities long before the phenomenon of community was clear elaborated and taught. Man must be able to develop and maintain himself in order to survive in a world that is becoming ever complex. Feasibility and visible evidences are not the actual evidences of development but the unity for creating a physical proof is what one must seek for.

The definition by Hugo is acceptable in this study because development is a very broad and difficult concept to define. Various definitions mention a process of transition from an acceptable situation to a relatively good environment. It is this process where changes occur resulting in what is called development.

Various communities are currently undergoing this process through the involvement of women in community projects that bring about changes in the social life of the community. Instead of being housebound, women now are moving out of their homes to meet others and engage themselves in community activities. The economic perspective fits because having different social problems associated with poverty, women try to improve their economic status as they get an income while on the other hand they contribute in improving economy, it is therefore enough matter of fact for convincing the researcher that communities are continuously evolving around the globe and change is a constant.

\section{Community Development}

By the definition that we propose, it counts the education, healthcare and community building aspects of local people service provision by non-government organizations and 
government. Even more generally, individuals and organizations in the community development system range from neighborhood resident to allies in the federal government who fight years after years to keep particular funding in the federal budget (Ronald \& William, 2011).

Be Beer \& Swanepoel (1998), explains the importance of community development by claiming that 'Since the social-structural aspect of community vary from place to place, community development should include no specific stipulation about social structures or relationships. Community development is also important because it expends opportunities. Jones (1982), describes community development as a method, a process, A program and a movement. These are explained as: A method of community development is regarded as a means to an end and not as an object in itself. Community development has a place as a program with focus on social, economic and political development. Community development is a process for changing communities towards desired goals. This includes study, education, training, planning, organizing and action that bring about cognitive purposeful change towards community goals. Community development is also described as a movement for participation by dedicated members who intend addressing their needs. Besides that, community development is concerned with task goals and process goals that help in achieving concrete objectives and help people grow or strengthen the qualities of participation, self-direction and co-operation (Lotz, 1998). Also, the application of the approach both to rural and urban communities differs because of the difference in these communities.

\section{Urban Community}

Since the focus of the study is urban community therefore in order to understand it well a clear look over the phenomenon is imperative. Sainsbury (1994), said that "the urban community means the city community". Fitzgrerald (1980), stipulates that most urban areas, experience similar social interaction. Quality education, adequate health care services, better water supply mechanism and properly arranged infrastructure are some remarkable aspects of an urban community.

Gilchrist (2004) stipulates that three substantive but interrelated meanings exist for this concept. The socio-cultural definition of urban rest on the assumption that behavioral and attitudinal differences exist between inhabitants of areas with low population densities (i.e., rural areas) and zones of high population density (i.e., urban areas). The

occupational definition rests on the dominance of industries in urban scales. The ecological definition of urban refers to areas in which settlements are massive, with no or less substantial zones between them.

All in all, one can summarize this concept to be referring to an area which is fill with all modern commodities and trends. However, it cannot be disputed that urban areas are affected by the societal changes caused by socio-economic factors. 


\section{Women in Community Development}

In this section, the focus is going to be put on the role of women in community development. In all the communities whether rural or urban, there are some rules, norms, customs and traditions for women specifically and despite having their internationally acclaimed social rights they follow the traditions and live accordingly. Some where women live in house and do household works, somewhere they work outside to earn bread and butter for their family. Somewhere they actively take part in politics and rule their nations and somewhere they spend their whole life saving lives of others behind the disguise of nurse and a doctor. As Chandra (1997) said that, in fact, everywhere their roles define the status of women in the community. However, social change and development requires that all local people be participated in community development programs in one way or another for the accomplishment of their roles within given statuses.

Mcnicol and Cain (1990) stated that in many urban communities men exercise control over women to such an extent that they prevent them from working outside the home. Development in the field of Economic among urban women is supposed to be growing at a larger scale as urban women normally have good education, awareness with the modern technologies and good grasp over the running trends in the society that, while they have a potential to develop their communities, they also have an obligation to improve the status of women and of their households.

El Ghonemy (1991) states that most countries have now established women's units within the governmental machinery and in some countries women co-operatives have been formed. Subjected to the activities like commercial and technical works, it has been understood that there is no positive results without urban women participations this has consequently led to anions for developing the position and output of urban women.

\section{The Concept of Participation}

The term participation is being used throughout the world in different sectors, and that has got very boarder range of meanings. It is not easily to define it with a specific term, it may take many types, which is farmed from one another. People participation is very important because their participation increase programs or projects effectiveness and success to promote self-sufficiency among the participants and to boost the figures of people who potentially can advantage from development.

People's participation is not a complicated concept of development. It refers to the ordered reality of human practice, to people's day-to-day encounters and their experiments with the household environment, natural resources, animals or plants in their social laboratories. It is their interactions and strategies in the organization of family life 
which are the crucial point from which participatory development should start (Langton, 1978). To elaborate the phenomenon further and its close affiliation to the proposed study, following distinctions are necessary to understand.

\section{Community Participation}

Since it is a clear crystal fact that the principal aim of the following explanation is to define the relationship between community participation and community development. Community development is actually a specific form of community participation, the success of which is determined by two factors - The role of the state and the complexity of the decision making taking place at the core of the community participation process.

As Ife, J (1999), stated that community participation make the people capable to take development initiatives at local level, which leads to successful implementation of programs. Participation needs institutional capacity which boosts local communities towards aspirations. Financial power is very important for any development, therefore, community participation becomes an essential in strengthening economical strength of local communities and governments to boost local communities or government revenue and competent to solve the locally raised problems with available resources. The key aims of community participation is to involve the local people in decisions, planning, implementation and evaluation process.

\section{Women and Community Participation}

Women participation in various programs and development problem is a international fact which is being discussed and analyzed by experts and scholars throughout the world. A great result has achieved by women in the community development programs in the world (Cheston \& Kuhan, 2002). However, there is still need a lot to remove disparity between women and their male counterparts in all fields. According to Brydon and Chant (1989), it is obvious that the development towards women involvement in community development programs has encountered barriers at the institutional level in the world. Among traditional societies of the world, men and women were assigned different roles.

Since 1980, women participation has identified in all fields in the world specially in developed countries and comprise around 40 percent of workers worldwide (ILO, 2008). According to Wise (1998) in many countries, women enrollment in schools, colleges and universities is higher as compared with men and they also control specific economic segments as in the educational and nursing departments. But this fact, however, does not equal opportunities to women to get equal access. Although thousand of women qualified and have the skills for management jobs but mostly Third World countries deprive them for it. 
In spite of the intense and powerful work, women are seen by policy makers and nongovernment organizations primarily as a groundwork of voluntary labor for community development interventions and their priceless socio-economic input goes unknown. In community development programs, women have remained deprived (FranseUa \& Frost, 1977). This concept guesses that women have the inspiration, dream, and capacity for positions of power and status, but unseen obstacles remain them from succession the top even in local community organizations. The glass ceiling refers to the artificial barriers based on attitudinal or organizational prejudice that put off competent individuals from advancing upwards in their organization into management level positions (World Bank, 1990). That is why it is needed to search aspects disturbing women involvement in community development programs or projects.

\section{Women Awareness about Community Participation}

Gender related issues are very critical issues in community development today. Women participation in community development may improve their economic wellbeing (Mayoux, 2002). Across the developing world, studies show that women's participation in community initiatives can have long-lasting benefits for women and children. Women who are empowered to take action, whether through programs led by governments, nongovernmental organizations or those driven by the community, often have a positive influence on the lives of other women.

On a different horizon, if we elevate the phenomenon of participation of women in the community development referenced to the urban community development and consider its importance subjected to the children of a community and then relate the phenomenon with general women awareness about the community participation there we will come to know that it is currently a serious matter of interest for major developing countries because children for any nation are the builders of a new future and if their present is not secured well in regards of healthcare, education and other basic needs then the prosperous and progressive future can never be guaranteed for the nation (Kgarimetsa,1992). Since women have a very close connection to children as compared to their opposite gender, therefore, a great responsibility lie upon their shoulders that require their participation and if they lack awareness in this sense then it is an indication of fall for the community, nation and mechanically the country.

Normally, it is observed that rural women lack awareness in all matters of interest but it must not be a shocking fact for one that the women from urban community also lack awareness in most of the affairs of community development. In a Quarterly report submitted to National Endowment for Democracy (NED), Health and rural Development in Balochistan (HARD-Balochistan) 2017-2018 claimed that in the most urban area of Balochistan, the Capital Quetta city, majority of women lack awareness towards their 
basic, social, civic, socio-economic, political and democratic rights and do not carry their national identity as they do not have their computerized national identity cards (CNICs) so that they are not officially considered as the resident and citizen of Pakistan. Moreover, it was claimed in the study that women are intentionally kept unaware of their role in the development and the women to in those urban areas do not take it as a serious matter of interest because of lack of knowledge, lack of interest and quite troublesome literacy rate. Above mentioned example clearly indicates and elaborates that it is not the resources that matter but it is interest and sense of realization and responsibility that takes a community, society and nation to the peaks of successes. Women are indeed a very important stakeholder in the progress of any society and if they are kept unaware then collapse is destined for the nation. Therefore, women's awareness about community participation for community development is as essential for a nation as oxygen for respiration to an individual.

\section{Area of Study}

The focus of this study was Balochistan province of Pakistan. Balochistan is one of the four provinces of the Islamic Republic of Pakistan. Balochistan was established as a separate province in its present form in 1970. Balochistan, province of Pakistan is by far the largest in size and the smallest in population. The Province covers 34.7 million hectares, almost $44 \%$ of the country's land area, with a population of about 8 million people (12 persons per sq. km.). The province is located in South-Western (220N to $320 \mathrm{~N}, 660 \mathrm{E}$ to $700 \mathrm{E}$ ) Pakistan. About $80 \%$ of the area can be classified as intermountainous. The remaining $20 \%$ consists of flood plains and coastal plains. The Province is divided into 30 districts $(\mathrm{GoB}, 2006)$.

\section{Research Methodology}

This section of the study deals with methods and tools used in the collection and analysis of the data. This article is based on a study that investigates the experiences of women participation in community development programs in urban areas of Balochistan. For data collection, the researcher used technique of questionnaire. Pre-structured questionnaire was prepared for all participants. The aim of using questionnaire to know their perception about women participation in community development in the urban areas of Balochistan. As stated by Ranjit (2009), "the researcher wants to know what is in and on someone else's mind". The primary data was collected from 100 respondents throughout Balochistan at urban areas and the relevant secondary data was collected through a variety of sources such as websites, Economic survey, books and journals. The purposive and convenience techniques of non-probability sampling method applied. 


\section{Results and Discussion}

First of all, the participation of the women is key to the success of community development programs. In the absence of women participation, the programs are plagued to be failed. The above programs were implemented to empower and protect the poorest of the poor people specially deprived women. According to the study findings, the programs did not fulfill the expectations and did not help to improve the living conditions of women. However, programs created some job opportunities for the influencers people and made some positive impact on income distribution in the urban areas.

Table: 1

Necessary of women participation in community development programs

\begin{tabular}{|l|c|c|}
\hline Necessary of Women participation in CDPs & Frequency & Percentage \\
\hline Yes & 90 & $90 \%$ \\
\hline No & 10 & $10 \%$ \\
\hline Total & $\mathbf{1 0 0}$ & $\mathbf{1 0 0 \%}$ \\
\hline
\end{tabular}

\section{Interpretation of Data}

The above table about the question do you think women participation is necessary in CDPs? The above cited information raveled that $90 \%$ respondents marked on option Yes, which much higher compare to $10 \%$ respondents marked on option No. According to the findings, women participation in community development programs is very essential specially in urban areas because their participation in community development programs can make the process of development much advance. The role of women in community development has become very crucial and can be the means to reducing gender inequality, ending thousand years of discrimination and developing whole community. In some parts of the world, they have became as leaders in community development and successfully achieved the abilities and skills that have brought constructive changes to their targeted communities. According to the respondents, government and NGOs should make women participation oblige in all projects without women involvement projects should not be approved.

Table: 2

Factor motivate you to participate in CDPs

\begin{tabular}{|l|c|c|}
\hline Factors motivating participation in CDPs & Frequency & Percentage \\
\hline Improve community & 30 & $30 \%$ \\
\hline Social change & 60 & $60 \%$ \\
\hline Feeling of attachment & 10 & $10 \%$ \\
\hline Total & $\mathbf{1 0 0}$ & $\mathbf{1 0 0 \%}$ \\
\hline
\end{tabular}




\section{Interpretation of Data}

Table number no. 2 is about the question what factors motivated you to participate in CDPs? The above cited information raveled that $60 \%$ respondents believed social change is the most crucial factor for them to participate in CDPs, which much highest in ratio compare to $30 \%$ respondents mentioned that they are motivated by the motive that these programs improve community conditions. While $10 \%$ respondents mentioned that feeling of attachment with members of community and feeling of ownership with the project motivated them to participate in CDPs.

Women also wish to come forward to contribute something for the betterment of the country. But, unfortunately, women are not being encourage for it. Since 1947, women face social, cultural, political and economic challenges and obstacles and in some cases defeating those challenges and barriers become their inspiration. On other side, their broad and participatory approaches have persuaded the process of community development, women's contributions have been neglected in politics and comparatively inactive in community development programs because of socio-economic and cultural limitations. They also have great ambitions to come forward and contribute something for the betterment of community particularly for women.

Table: 3

Initially, what types of problems you have faced in CDPs

\begin{tabular}{|l|c|c|}
\hline Problems faced in CDPs & Frequency & Percentage \\
\hline Cultural barrier & 30 & $30 \%$ \\
\hline Male dominancy & 40 & $40 \%$ \\
\hline Lake of funds & 40 & $40 \%$ \\
\hline Total & 100 & $100 \%$ \\
\hline
\end{tabular}

\section{Interpretation of Data}

Table number no.3 is about the question initially, what types of problem you have faced in CDPs? The above cited information raveled that $30 \%$ respondents mentioned that they are mostly victims of cultural difference and barrier in CDPs, $40 \%$ respondents mentioned that they are motivated that male dormancy is the major problem they face in CDPs. While other $40 \%$ respondents mentioned that lake of funds is the problem they often face in CDPs.

Culture is the one of the main confront for women in our society because most of women loss their self-confidence to take part in polities particularly in community development programs. for example, traditions of veil (purdah), gender discrimination and other socalled customs. It will take more years to mobilize the community specially men to 
understand that without women participation it is not possible to move forward, for becoming a better and developed society it is very a vital to involve women in development process. Those people should be encouraged by government, NGOs and communities members who always have negative attitude for women.

Table: 4

Programs impacts on women lives

\begin{tabular}{|l|c|c|}
\hline Programs impacts on women lives & Frequency & Percentage \\
\hline Very satisfy & 10 & $30 \%$ \\
\hline Satisfy & 40 & $40 \%$ \\
\hline To some extent & 40 & $40 \%$ \\
\hline Poor & 10 & $40 \%$ \\
\hline Total & $\mathbf{1 0 0}$ & $\mathbf{1 0 0} \%$ \\
\hline
\end{tabular}

\section{Interpretation of Data}

Table number no. 4 is about the question what are the impacts of these programs on women lives? The above cited information raveled that $10 \%$ respondents mentioned that they are very satisfied with these programs, $40 \%$ respondents mentioned that they are just satisfied. While other $40 \%$ respondents mentioned that they are satisfied in some extent and $10 \%$ respondents show poor response regarding their satisfaction level with these programs.

A number of community development programs have also commonly found positive impact in this connection. It is found that those who have participated in projects become much empower in their decisions to challenge or transform power relations that impede gender equality. Women involvement in community development programs improved quality level of education, health and livelihood and tremendously useful to empower and make stronger the women in our society which is male dominated society .At the same, said that the role of community development programs play an essential role in women empowerment among working through opportunities and encouraging their potentials.

\section{Conclusions and Recommendations}

There were several crucial findings were traced during the data collection process form the respondents of urban areas of Balochistan, in regard of community development programs and the role of community members regarding their rights and responsibilities as members of community member, research study concluded that community development programs are very necessary for the development of urban communities. Research study also concluded that it is required for the community to build relationship with NGOs, governments as well as community as all should for the better purpose of community development. 
The study concludes that most of respondents that were very much concerned about the situation of their community and mentioned that there are some serious issues which are needed to be sort out like problems of women empowerment.

This study indicates that improvement and advancement of community development are highly dependable on the role of NGOs, government and community members especially in Balochistan it needs some serious actions to improve the living slandered of community members. It is somehow crystal clear that with help of community organization, NGOs and government communities can achieve goals and objective of community development.

In the present study researcher concluded that community development programs are affected by different factors like gender gap, corruption, poverty, inequity, cultural norms and values, these are main causative factors behind the decline of community development. These problems get greatly influence the conditions of community development programs in urban areas of Balochistan, due to which mostly people didn't participate in CDPs which can make the great differences among the people of community and NGOs/ governmental efforts to improve the living standard of people in community.

The current study also explores the causative factors behind the decline of community development programs in urban areas of Baluchistan. The literature revealed that the present system of community development is not performing well and this knowledge about the problems and prospects of community development will help the reader to understand the present status and find the possible solution for community faced in the other urban areas and will support to getting novel ideas. The development of a society depends to a large extent on the standard and nature of community development programs. It is the responsibility of NGOs, government and members of community to produce knowledgeable, far-sighted competent people, equipping them advance knowledge and skills to fill the sphere of societies and the various responsibilities to lead the community in a proper manner for the development of community in refence of community needs and demand.

This study on women participation in community development programs in urban community Balochistan researcher concluded that the community developments programs play a vital role in human resource development which is the very much crucial assed for building a great community and society. Investment and complete check balance of these programs are the resources only lacking factor which is creating a void to be filled by taking certain bold decisions. It raises the productivity and efficiency of individuals and thus produces skilled manpower that can lead the community towards the path of sustainable community growth and development. CDPs provides the base for 
socio-economic development. Similarly, to make the youth of the community an asset, attention should also be paid to vocational and technical training.

\section{Recommendations}

- There should be awareness programs to educate women to take participate in community development programs.

- Women in community must be provided with skills and knowledge about the development of community.

- There should be formed legislation and designed policies to stop political influence in the community development programs.

- Providing economic incentives to the community worker may encourage them to work more seriously and harder for better improved system in the community.

- Local government system is helpful in community development programs. In local government system the funds for community would be spent on a need basis by the locality..

- Community members should work effectively to improve the authority limit of network individuals, pioneers, and gatherings inside the network. By encouraging the latest open gatherings in a way that urged network members to share their perspectives in a valuable, obliging way, and stressing how the city acknowledges input, and will keep on being receptive to questions essentially helped the procedure.

- Community development programs should connect with network individuals in finding out about and understanding network issues, and the financial, social, ecological, political, mental, and different effects related with elective blueprints. The city considered various options in contrast to making drinking water upgrades. The city confronted a consistence issue with respect to water weight which should have been routed to meet State necessities. The all-inclusive strategy recognized some of extra insufficiencies in the water framework, including circulation lines, fire hydrants, and capacity.

\section{References}

Be Beer, F. \& Swanepoel, H. (1998). Community Development and Beyond. National Books Printers, South Africa.

Brydon. L. \& Chant, S. (1989): Women in the Third World. Gender Issues in Rural and Urban Areas. Edward Elgar Publishing Limited. England.

Cheston \& Kuhan. (2002). Empowering Women through Microfinance. Draft Report of Women's Opportunity Fund and Gems of Hope, USA. 
Chandra, S. K. (1997). Women and Empowerment. Indian Journal of Public Administration, vol.43:4, pp.395-99.

Dunham. A. (1970): The New Community Organization. Thomas Y. Crowell Company. Peacock.

El Ghonemy, M.R. (ed) (1991). Development strategies for the rural poor. Food and Agriculture Organization of the United Nations, Rome.

Ferrinho. H. (1980): Towards a Theory of Community Development. The Rustica Press. Cape Town

FranseUa, F. and Frost. K. ([977): On Being a Woman. Tavistock Publications. London.

Fitzgrerald, M. (1980). Urban Community Development in South Africa. McGraw-Hill, Johannesburg

Gilchrist, A. (2004). The Well-Connected Community a Networking Approach to Community Development.UK: Policy Press.

Government of Balochistan.(2006). Provincial Disaster Risk Management plan. UNDP Publication, Quetta.

Hugo, E.:(1984). Community Work as an Integral Part of Community Development. Social Work, vo1.20, pp.204-210.

Ismail, Maimunah (1999). Extension: Implications on Community Development. Dewan Bahasa dan Pustaka, Kuala Lumpur

ILO. (2008). Employment, Growth and Basic Needs: A One-World Problem, Geneva: ILO.

Ife, J. (1999). Community development: Creating community alternatives - vision, analysis and practice. Melbourne, Australia: Longman.

Jones, G. E. (1982). Progress in Rural Extension and Community Development. John Wiley and Sons, London.

Kenny, S. (1994). Developing Communities for the Future: Community Development in Australia. Melbourne, Australia: Thomas Nelson Australia. 
Kabeer, Naila (2005). Gender Equality and Women's Empowerment: A Critical Analysis of the Third Millennium Development Goal. Gender and Development, vol.13:1, pp.13-24.

Kgarimetsa, M. (1992). The Two Faces of Poverty - Urban and Rural. Social Work Practice, Vol.3.

Langton, S. (1978). What is citizen participation? . Lexington, USA: Lexington, MA.

Lotz, J. (1998). Lichen factor: the quest for community development in Canada. UCCB Press, Canada.

Pawan, Manohar. (2014). Social and Community Development Practice. Saurabh Printers Pvt. Limed, Delhi.

Kathleen M. MacQueen, et al. (2001). What Is Community? An Evidence-Based Definition for Participatory Public Health, American Journal of Public Health, vol.91:12, pp.1929-1938.

Korten, D.C. (1990). Getting to the 21st Century: Voluntary Action and the Global Agenda. West Hartford, Hartford: Kumarian Press.

McNicoll. G. \& Cain. M. (ed) (1990). Rural Development and Population: Institutions and Policv. Oxford University Press. New York.

Mayoux, L. (2002)." Women's Empowerment versus Sustainability? Towards A New paradigm in Microfinance Programs" in Lemireet. al. eds. Chapter 14.pp.245-70.

Noreen, S. (2011). Role of Microfinance in Empowerment of Female Population of Bahawalpur District, International Conference on Economics and Finance Research, 4(20).65-71.

Ronald F. Ferguson and William T. Dicken.(2011) Urban Problems and Community Development. London, Brookings Institution Press.

Ranjit, Kumar (2009). Research Methodology: A Step By Step Guide for Beginners. New Delhi, India: SAGA Publication.

Sultan, Shoaib (2009). The Aga Khan Rural Support Program: A Journey through Grassroots Development. Karachi, Pakistan: Oxford University Press. 
Sainsbury, D. (1994). Gendering Welfare States. Sage Publications. London.

United Nations (2007). Empowerment of Women Throughout the Life Cycle as a Transformative Strategy for Poverty Eradication. New York, USA: UNO Publisher.

United Nation. (1973). Popular Participation in Decision Making for Development. New York, USA; UNO Publications.

Wise, G.(1998). Definition: Community Development and Community Based Education. Masdison, USA: University of Wisconsin Extension service.

World Bank.(1990). World Development Report: Knowledge for Development. New York, USA: Oxford University Press.

Dr. Siraj Bashir is an Assistant Professor in the Department of Social Work, University of Balochistan, Quetta. 